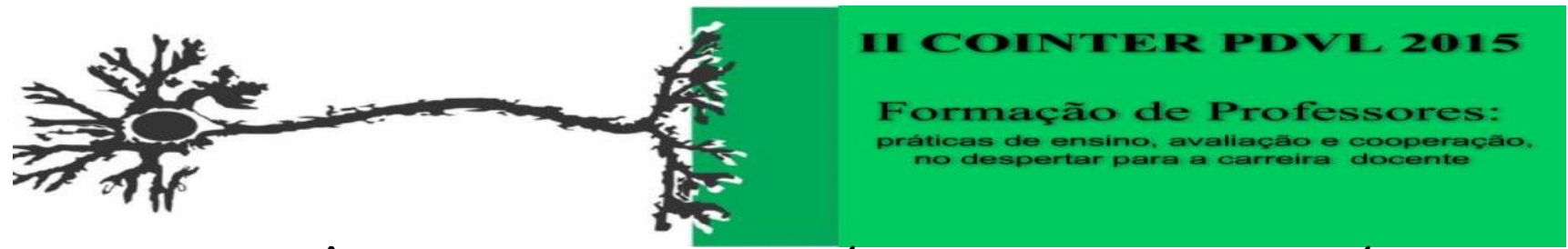

\title{
A IMPORTÂNCIA DAS ATIVIDADES PRÁTICAS NO ENSNINO DE QUÍMICA
}

\author{
Apresentação: Comunicação Oral \\ José Valmir Alves Junior ${ }^{1}$; Déborah Monteiro Barbosa²; Williana Vanessa da Silva ${ }^{3}$; Claudio \\ Henrique Alves Perdigão ${ }^{4}$
}

\begin{abstract}
Resumo
A presente pesquisa trata de uma atividade realizada com alunos e professor da $1^{\text {a }}$ série do ensino médio, de uma escola de referencia em ensino médio. Traz a importância da experimentação no ensino de química em uma escola na qual possui um cenário bastante diferente da realidade refletida por todos os pensadores modernos da educação. Levamos um momento reflexivo e de bastante conhecimento experimental e teórico para que os alunos pudessem vivenciar de perto a realidade de experimentação da química, e assim poder expor todos os seus pensamentos a respeito da presença e ausência das atividades práticas na sala de aula e em todo ambiente escolar. Dessa forma, podemos ver de perto também a opinião e explicação dos professores a respeito de tal problemática, e procuramos melhorar suas concepções por meio de um momento de diálogo após as práticas experimentais realizadas. A química está relacionada diretamente às necessidades básicas de todos os seres humanos tais como: alimentação, saúde, transporte entre outros e as pessoas devem compreender tudo isso. O ensino de química deve desenvolver nos alunos a capacidade de compreender os fenômenos químicos presente em seu dia-a-dia. A pesquisa também evidencia que as aulas típicas não emerge a compreensão do objetivo da realização do experimento, o que tende a provocar desinteresse. Todos os resultados que encontramos em meio ao diálogo com os alunos permitem argumentar em favor de atividades experimentais que incentivem os alunos a questionar, pesquisar, refletir, argumentar e agir, nos parâmetros e contextos que essa ciência tão relevante, engloba.
\end{abstract}

Palavras-Chave: Educação química, Práticas experimentais, Ensino-aprendizagem, Experimentação.

\footnotetext{
${ }^{1}$ Bacharelado em Engenharia Florestal, UFRPE, valmirjunior.edu@hotmail.com.br

${ }^{2}$ Bacharelado em Engenharia Florestal, UFRPE, deinhamonteirob@gmail.com

${ }^{3}$ Licenciatura Plena em Química, IFPE, Nessah.silvaa@gmail.com

${ }^{4}$ Mestre em Ciências, IFPE, Claudio.perdigão@vitoria.ifpe.edu.br
} 


\section{Introdução}

O objetivo da Química é compreende a natureza e todas as suas transformações, sendo os experimentos bastante relevantes para que os alunos tenham uma compreensão mais científica das transformações que nela ocorrem. Saber as fórmulas, decorar reações e propriedades, sem conseguir relacioná-los com a natureza e suas práticas diárias, não é conhecer Química. Essa não é uma ciência estática.. O ensino tradicional é administrado de forma que o aluno só saiba inúmeras fórmulas, decore as reações, mas sem relacioná-las com seu cotidiano.

Pesquisas recentes apontam para o favorecimento de uma aprendizagem significativa utilizando as aulas práticas como principal recurso didático e, este trabalho se propõe a verificar se a experimentação realmente favorece a aprendizagem de forma significativa. Tendo em vista que, esse público ficou à margem de ter acesso ao conhecimento de forma dialogada durante décadas.

Uma estratégia docente no uso de Experimentos Demonstrativos no Ensino de Química é a prática constante por parte dos professores, tendo em vista a visualização na grande parte dos conteúdos de uma forma prática, construtiva e eficaz, fazendo com que os alunos possam compreender inteiramente todos os processos que torne essa disciplina ainda mais educativa entre os alunos.

De acordo com Maria (2001) os alunos costumam atribuir à prática experimental um caráter motivador, significativo e essencialmente vinculado aos sentidos. Assim, o ensino de Química torna-se sacrificado quando da ausência de aulas dinâmicas que estimulem a percepção, criatividade e interesse dos alunos. Tornando-se uma verdadeira monotonia e fazendo com que os alunos não sintam estimulo algum em seguir as abordagens do professor em sala de aula.

\section{Fundamentação Teórica}

Chama-se atenção ao fato de a ausência de atividades experimentais no ensino de Química não estar relacionada diretamente à inexistência de laboratório ou à inexistência de materiais e vidrarias. Em muitas escolas há o aparato material necessário, entretanto as práticas não ocorrem. Muitas vezes há a limitação informacional e/ou até de formação dos professores sobre aspectos relacionados ao manuseio de equipamentos e materiais disponíveis, ou mesmo uma desinformação com relação às possibilidades de realização de práticas experimentais. Colabora para isso o exíguo acesso a publicações com experiências de inovação na área. Isso acaba por dificultar a prática pedagógica de uma Ciência com bases Experimentais, prejudicando assim, a mediação docente no ensino-aprendizado. Assim, entender a realidade experimental em Química de uma escola é bastante relevante para que possamos saber a verdadeira realidade do cenário da educação química. 
Esses fatores de conhecer a verdade por trás das salas de aulas refletem na qualidade da educação, na formação de novos profissionais e principalmente na vida de todos os estudantes que partilham diariamente desse sistema. Encontramos base legal para tal discussão no texto dos Parâmetros Curriculares Nacionais, que afirmam que

\footnotetext{
“a experimentação na escola média tem função pedagógica, diferentemente da experiência conduzida pelo cientista. A experimentação formal em laboratórios didáticos, por si só, não soluciona o problema de ensinoaprendizagem em química. As atividades experimentais podem ser realizadas na sala de aula, por demonstração, em visitas e por outras modalidades".
}

Portanto, podemos evidenciar que a utilização de Experimentos Demonstrativos em sala de aula é uma boa proposta pois faz surgir uma possibilidade de maior dinamização das aulas de Química, despertando assim o interesse dos alunos, tornando os conteúdos mais potencialmente significativos, em consonância com as teorias de autores construtivistas como Ausubel e Vygotsky. Isso vem sendo evidenciado cada vez mais e a cada evento científico em que se abrem espaços para discussões a respeito desse tópico, pois toda uma geração de educadores está sendo preparada em sala de aula para lutar justamente contra esse ensino metódico e tradicionalista. Queremos sim, alunos conscientes do que estejam fazendo, e que possa levar para além dos muros da escola, todo conhecimento adquirido em sala de aula.

\section{Metodologia}

Através da visita ao campo de pesquisa que foi a Escola de Referência em Ensino Médio Carlos Soares da Silva pretende-se realizar uma apresentação a toda comunidade escolar, da prática envolvendo Experimentos Demonstrativos no Ensino de Química, isso como ponto de partida para a discussão sobre aspectos experimentais. Utilizamos como sujeito de pesquisa os estudantes do $1^{\circ}$ ano do ensino médio da escola, como também o professor de química da turma.

Após a apresentação dos experimentos demonstrativos tivemos um momento de reflexão junto aos alunos, onde foram elaboradas algumas questões norteadoras para que pudéssemos entender e compreender quais são os pontos de vista dos alunos acerca da experimentação, e se com a parte prática conseguiram assimilar alguns conteúdos teóricos com a prática. $\mathrm{E}$ baseado em suas opiniões, elencamos os principais tópicos elencados pelos discentes. 


\section{Resultados e Discussão}

A partir da análise do momento de discussão construtiva, ao longo da prática experimental e o momento disponibilizado para diálogo, podemos obter algumas respostas de grande importância para que pudéssemos entender a realidade de professores e alunos diante da disciplina de Química.

Analisando as opiniões que presenciamos a partir dos questionamentos que foram feitos aos alunos, podemos entender como eles veem a Química em sala de aula e no seu dia-a-dia. Quando questionados a cerca das principais dificuldades encontradas na disciplina $80 \%$ dos alunos responderam que sentem dificuldades em não conseguir assimilar os conteúdos estudados em sala com o seu cotidiano, e onde irá utilizar no decorrer de sua vida.

Quando questionados sobre como gostariam que a Química fosse abordada em sala, os estudantes responderam que gostariam que a disciplina fosse mais dinâmica, mais interessante, que tivesse mais aulas práticas para que eles pudessem visualizar os fenômenos que ocorrem na Química e assim pudessem entender melhor o conteúdo abordado em sala. Em resumo, disseram que as aulas poderiam ser justamente igual à demonstração prática que fizemos, atrelando a teoria a prática, de uma forma inteiramente dinâmica.

Ao ser questionado a cerca da associação da Química da sala de aula com a Química do diaa-dia, $60 \%$ dos alunos ainda não consegue visualizar esta relação, muitos só associam a Química a materiais de alta periculosidade e não conseguem entender que a Química podem estar presente em pequenas transformações e fenômenos do nosso cotidiano, como por exemplo, na digestão de alimentos em nosso organismo, na fotossíntese das plantas.

Os professores de Química que participaram do momento de discussão, a partir de suas respostas, em relação às principais dificuldades dos alunos, o professor afirma que não faze o uso pelo fato da escola não ter este espaço, e também pelo fato do laboratório não ter na maioria das vezes os materiais necessários para realização das práticas.

A partir dão momento de discussão, destacamos que estudos anteriores realizados por PERDIGÃO E LIMA (2010) dão indícios de que a experimentação em Química exerce um papel fundamental no ensino aprendizado, se não vejamos: a apatia com relação à disciplina pode estar relacionada à total ausência experimental ou à separação que se está percebendo entre as aulas práticas e as aulas teóricas, assim, nessas últimas privilegia-se a abstração em detrimento da observação concreta de fenômenos.

A partir das respostas dos alunos que participaram da pesquisa podemos entender que a associação da teoria com a prática é grande importância para a aprendizagem dos alunos, pois como afirma RUSSEL (1994), a aprendizagem de Química torna-se mais sólida quanto mais houver a 
integração entre teoria e prática, cumprindo assim sua funcionalidade no ensino, interagindo de forma diversificada os conteúdos trabalhados em sala de aula com os experimentos.

Foram realizados alguns dos experimentos a seguir:

Figura 1. Enchendo o balão

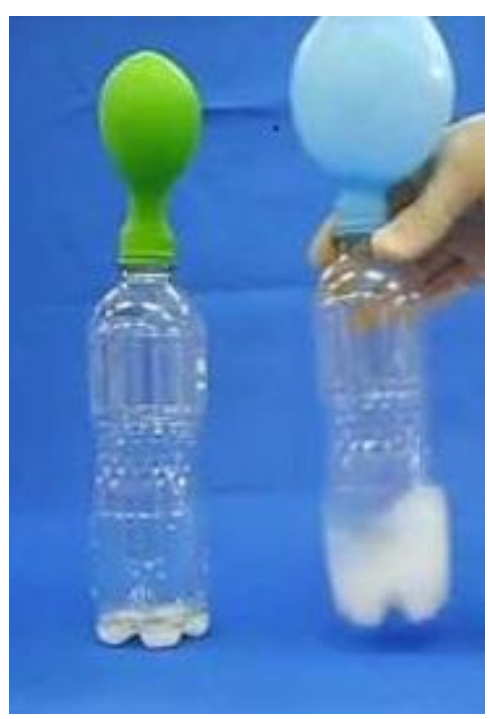

Figura 2. Solubilidade entre os compostos

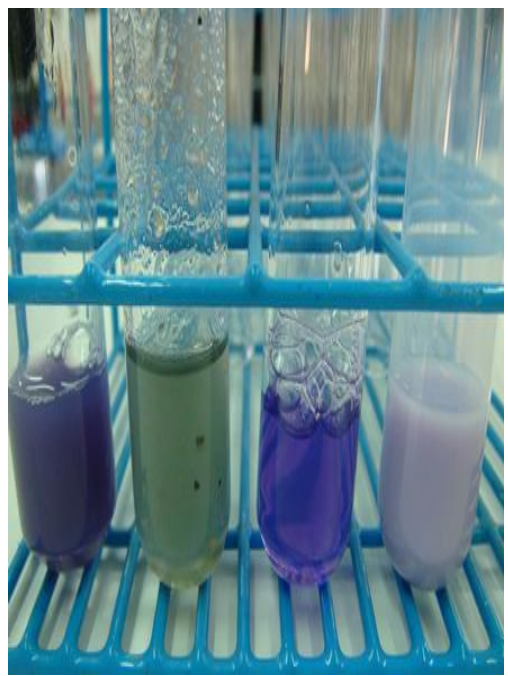


Figura 3. Demonstração da densidade

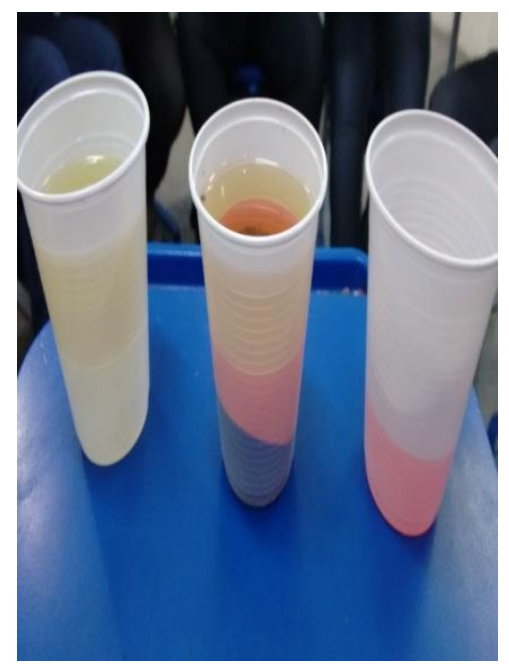

Figura 4. Condutividade elétrica

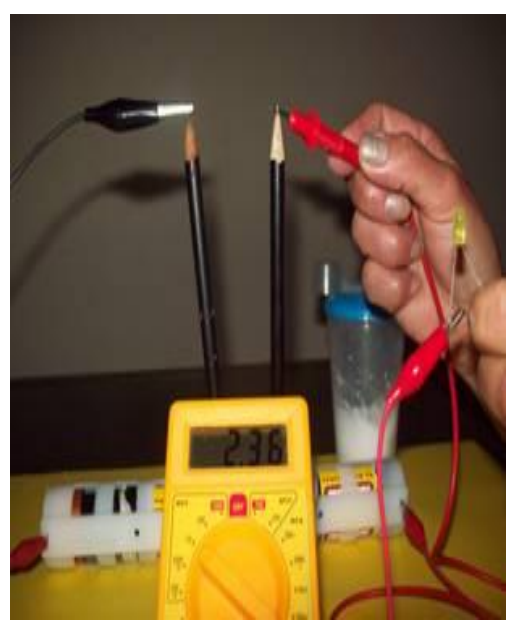

\section{Conclusões}

Antes de tudo, podemos destacar a relevância da pesquisa no sentido de ter levado para além dos muros da universidade, um momento bastante importante para toda comunidade escolar participante. Pois como não tinham uma rotina envolvendo práticas no ensino de química, puderam desfrutar de uma coisa que chama bastante atenção nessa ciência, que são todas as suas atividades práticas.

Momento único poder acompanhar os estudantes atentos a cada experimento e o melhor, perceber que naquele momento eles estavam parecer desvendar toda uma mística de seu cotidiano, a cada reação um brilho no olhar como se cada associação do momento fosse feita a uma parte de seu cotidiano, no derretimento de um picolé, na fervura de uma água. Tudo passava a ter um sentindo especial naquele momento. 
Baseado em todos esses aspectos, concluímos o quão é importante realizarmos o emparelhamento entre a teoria e a prática, importante no sentido de que o aluno possa compreender o que, e porque está estudando determinado conteúdo. É de suma importância que os professores além da escola não possuir espaço adequado para tal feito, vá em busca de alternativas para realizar todas as práticas pertinentes as teorias do ensino da química, para que fique assim, tudo caracterizado e explicado na consciência de nossos alunos.

\section{Referências}

ARRUDA, S. M.; LAGURU, E. C. Questões Atuais no Ensino de Ciências. Roberto Nardi (org.). São Paulo: Editora Escrituras, 1998.

BRASIL, Parâmetros Curriculares Nacionais: ciências naturais. Secretaria de Educação Fundamental. Brasília: 1998.

BORGFORD, C. L.; SUMMERLIN, L. R. Chemical activities. Washington: American Chemical Society, 1988.

DEMEO, S. Teaching Chemical Technique. Journal of Chemical Education. v.78, n. 3, p. 373. June, 2001.

EALY, J. B.; SUMMERLIN, L. R.; BORGFORD, C. L.. Chemical Demonstrations. A Sourcebook for Teachers. v.2, 2. ed. Washington: American Chemical Society, 1988.

EALY, J. B.; SUMMERLIN, L. R. Chemical Demonstrations. A Sourcebook for Teachers. v. 1, 2. ed. Washington: American Chemical Society, 1988.

GATTI, B. A. Grupo focal na pesquisa em Ciências sociais e humanas. Brasília: Líber editora, 2003.

HAMBURGER, E. W. O Desafio de Ensinar Ciências no Século XXI. São Paulo: Editora da Universidade de São Paulo, 2000.

HESS, S. Experimentos de Química com materiais domésticos. São Paulo: Moderna, 1997.

INEP. Programa Internacional de Avaliação de Alunos - PISA. Disponível em http://www.inep.gov.br/internacional/pisa/Novo/oquee.htm. Acesso em: 05 de outubro de 2007.

LOPES, A. R. C. Ensino de química e conhecimento cotidiano. 1998. Disponível em www.moderna.com.br/artigos/quimica/0026. Acesso em: 27 de janeiro de 2010.

MARIA, I. (et all). Ensino de química por meio de experimentos atrativos, simples de baixo custo. $24^{\circ}$ Reunião Anual da Sociedade Brasileira de Química. Maio, 2001. Disponível em: www.mec.gov.br/semtec/ftp/Ciências. Acesso em: 22 de janeiro de 2010.

MATEUS, A. L. Química na cabeça. Belo Horizonte: Editora UFMG, 2001.

MENEZES, L. C. Formação continuada de professores de ciências no contexto ibero-americano. São Paulo: NUNES, 1996. 
MONTES, L. D.; ROCKLEY, M. G. Teacher Perceptions in the Selection of Experiments. Journal of Chemical Education. v. 79, n.2, p. 244. June, 2001.

PEIXOTO, D. P. Ensino de Química e Cotidiano. Maio, 1999. Disponível em www.moderna.com.br/artigos/quimica/0025. Acesso em: 22 de fevereiro de 2010.

PERRENOUD, P. Dez novas competências para ensinar. Patrícia Chittoni Ramos (trad.). Porto Alegre: Artes Médicas Sul, 2000.

PERDIGÃO, C. H. A, LIMA, K, S. A prática docente experimental de Química no Ensino Médio. Anais do IV Educon. Aracaju - SE. Setembro de 2010.

SARQUIS, M.Recommendations for Offering Successful Professional Development Programs for Teachers. Journal of Chemical Education. v.78, n.6, p. 820. June, 2001. 